\title{
Multiple disguises for the same party: the concepts of morphogenesis and phenotypic variations in Cryptococcus neoformans ${ }^{\dagger}$
}

\author{
Oscar Zaragoza* \\ Mycology Reference Laboratory, National Centre for Microbiology, Instituto de Salud Carlos III, Madrid, Spain
}

\section{Edited by:}

Marcio Rodrigues, Federal University of Rio de Janeiro, Brazil

\section{Reviewed by:}

Andrew Alspaugh, Duke University

School of Medicine, USA

Kirsten Nielsen, University of

Minnesota, USA

\section{*Correspondence:}

Oscar Zaragoza, Mycology Reference Laboratory, National Centre for

Microbiology, Instituto de Salud

Carlos III, Carretera

Majadahonda-Pozuelo, Km2,

Majadahonda, 28220 Madrid, Spain.

e-mail:ozaragoza@isciii.es

\begin{abstract}
Although morphological transitions (such as hyphae and pseudohyphae formation) are a common feature among fungi, the encapsulated pathogenic yeast Cryptococcus neoformans is found during infection as blastoconidia. However, this fungus exhibits striking variations in cellular structure and size, which have important consequences during infection. This review will summarize the main aspects related with phenotypic and morphological variations in $C$. neoformans, which can be divided in three classes. Two of them are related to changes in the capsule, while the third one involves changes in the whole cell. The three morphological and phenotypic variations in $C$. neoformans can be classified as: (1) changes in capsule structure, (2) changes in capsule size, and (3) changes in the total size of the cell, which can be achieved by the formation of cryptococcal giant/titan cells or microforms. These changes have profound consequences on the interaction with the host, involving survival, phagocytosis escape and immune evasion and dissemination. This article will summarize the main features of these changes, and highlight their importance during the interaction with the host and how they contribute to the development of the disease.
\end{abstract}

Keywords: Cryptococcus neoformans, morphogenesis, capsule enlargement, giant cells, micro-cells, antigenic variations

\section{INTRODUCTION}

Adaptation of pathogenic fungi to the host environment is key to understanding the diseases caused by these microorganisms. During infection, adaptive responses are triggered to evade the immune response and survive in the host. Most of these responses are regulated by signaling pathways, which induce adaptation to the host nutritional environment, $\mathrm{pH}$ and osmotic pressure, and also provide resistance to free radicals and antimicrobial molecules. In addition, pathogenic fungi frequently change their cellular morphology. For example, it is well known how different yeasts induce pseudohyphae and hyphae during infection. These cellular forms have been well characterized in Candida albicans, and are produced by other Candida sp (Kurtzman and Fell, 1997; Whiteway and Bachewich, 2007). Filamentous fungi, such as Aspergillus spp also induce the formation of filaments after the germination of the spores during infection. Other fungi exhibit dimorphism regulated by the temperature, as happens with Histoplasma capsulatum and Blastomyces dermatitidis (Kane, 1984; Maresca and Kobayashi, 1989). These changes are important for the course of infection, and provide the fungus a mechanism to reach new nutritional environments, evade the host immune response, and disseminate through the organism.

The pathogenic fungus Cryptococcus neoformans represents a unique example of eukaryotic virulence. Its incidence increased

${ }^{\dagger}$ I dedicate this article to my two sons, Javier and David, for filling up my days with joy and happiness. significantly at the end of the twentieth century associated with the AIDS pandemic (Casadevall and Perfect, 1998). Recent studies identified that C. neoformans also accounts for $10 \%$ of fungal infections in transplant recipients (Singh and Forrest, 2009; Hosseini-Moghaddam and Husain, 2010). Although its incidence in countries where the highly active antiretroviral therapy (HAART) is available has decreased, its associated mortality is still high (Dromer et al., 2007). The incidence in developing countries remains unacceptable, since it has been estimated that $C$. neoformans causes more than 650,000 deaths per year in these countries (Park et al., 2009).

Cryptococcus neoformans possesses a complex polysaccharide capsule that surrounds the cell body. The capsule is the main virulence factor of the yeast because it exerts a large number of deleterious effects on the host (see review in Zaragoza et al., 2009). Among others, it confers resistance to stress conditions, such as dehydration, free radicals, and antimicrobial compounds (Aksenov et al., 1973; Zaragoza et al., 2008). The capsule can interfere with the host immune response at multiple levels. For example, it has antiphagocytic properties, inhibits Ab production, depletes complement, inhibits leukocyte migration, and induces apoptosis in macrophages and T cells (Murphy and Cozad, 1972; Kozel et al., 1977; Macher et al., 1978; Lipovsky et al., 2000; Vecchiarelli, 2000; Ellerbroek et al., 2002; Monari et al., 2006). In addition, C. neoformans expresses other virulence factors during infection, such as cell wall melanin, proteases, and phospholipases (see reviews in Casadevall and Perfect, 1998; Nosanchuk and Casadevall, 2003; Heitman et al., 2011). 
Cryptococcus neoformans has traditionally been considered a yeast that does not exhibit filamentous growth or dimorphism, except during the mating process (for reviews, see Heitman et al., 2011; Kozubowski and Heitman, 2011). Although some pseudohyphal forms have occasionally been described during infection (Neilson et al., 1978; Williamson et al., 1996; Gazzoni et al., 2010), this is a rare phenomenon, and it is believed that $C$. neoformans does not undergo morphological changes in the host. While this concept is true, many articles demonstrate that $C$. neoformans displays a complex morphogenetic program which results in the appearance of multiple phenotypic forms. In fact, the final result of these variations is the production of multiple types of yeast cells that may differ in their recognition by the immune system.

In this review, I discuss the concepts of phenotypic and morphologic variations in C. neoformans with the purpose of illustrating the complexity of different forms that this pathogen exhibits in vivo and how they contribute to the development of the disease. These changes are of three types: changes in capsule structure, changes in capsule size, and changes in total cell size. Some of these different variations are illustrated in Figure 1. I describe the main characteristics of these variations, and also highlight their importance in infection.

\section{CHANGES IN CAPSULE STRUCTURE}

The capsule of $C$. neoformans is mainly composed of polysaccharide. The major component is glucuronoxylomannan (GXM), which comprises around 90-95\% of the total mass of the capsule (Cherniak et al., 1980). The other component has been classically known as galactoxylomannan (GalXM; Cherniak et al., 1982), which accounts for $5-10 \%$ of the capsular polysaccharide. Both components have high molecular weights, around $10^{6}$ Da for GXM and $10^{5}$ Da for GalXM (Cherniak et al., 1982; McFadden et al.,

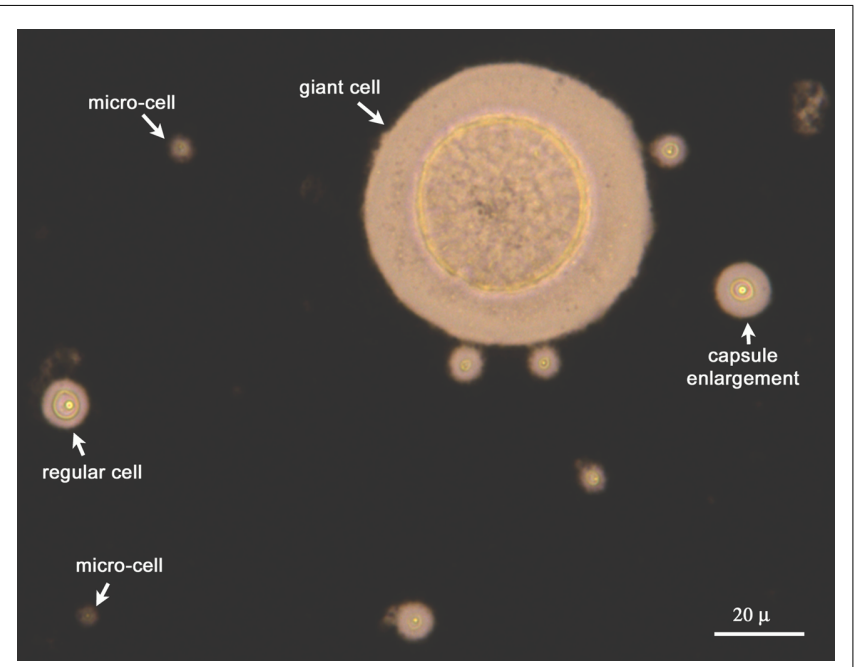

FIGURE 1 | Heterogeneity of fungal population extracted from the lungs of infected mice. The yeast cells isolated from the lungs of infected mice were isolated and suspended in India Ink to visualize the capsule. As shown, multiple forms of $C$. neoformans (regular cells, cells with enlarged capsule, fungal giant/titan cells, and microforms) are present during infection. 2006b). The structure of these polysaccharides has been largely studied and revised (see reviews in Doering, 2000; Bose et al., 2003; Janbon, 2004; Zaragoza et al., 2009; Janbon and Doering, 2011). Briefly, GXM is composed of a chain of mannose residues, with substitutions of xylose and glucuronic acid. GalXM was previously believed to be composed of a chain of galactose with substitutions of xylose and mannose. Recently, it was found that it also contains residues of glucuronic acid (Heiss et al., 2009), so the name of glucuronoxylomannangalactan (GXMGal) has been suggested for this polysaccharide. GXM is highly 6-O-acetylated (Cherniak et al., 1988a; Cherniak and Sundstrom, 1994; Janbon et al., 2001; McFadden et al., 2006b). In addition to polysaccharides, the capsule consists of a small proportion of mannoproteins (MPs; Levitz and Specht, 2006). While GXM localizes throughout the whole capsule, GXMGal and MPs seem to localize in regions close to the cell wall (De Jesus et al., 2010). More recently, other components have been suggested to be present in the capsule too, such as sialic acid and chitin-like structures (Rodrigues et al., 2008; Gahrs et al., 2009), but their role in capsule architecture remains unknown.

The steps involved in capsule synthesis and fibers assembly are poorly understood. A few capsular genes necessary to produce the capsule (known as CAP) have been described (Chang and Kwon-Chung, 1994, 1998, 1999; Chang et al., 1995), but their exact biochemical function is not fully characterized. More recently, more genes have been identified by massive analysis of a C. neoformans mutant library (Liu et al., 2008), but the interplay of these, and how they regulate capsule synthesis remains to be elucidated. Furthermore, it has been shown that secretion of vesicles loaded with capsular polysaccharide is an important process in capsule synthesis (Rodrigues et al., 2007).

Although the main components of the capsule are characterized, how the polysaccharides are spatially organized is still unknown. The polysaccharide is organized in fibers that can selfassociate through non-covalent interactions (Pierini and Doering, 2001; McFadden et al., 2006b). In the case of GXM, seven different basic structures have been described (Cherniak et al., 1998; Nimrichter et al., 2007), but how these structures are organized, and repeated is still unknown. Recent findings indicate that the capsular fibers are highly branched (Cordero et al., 2011). A clear conclusion from the basic analysis of the capsule is that multiple structures, repetitions, and ramifications are possible in the same GXM or GXMGal molecule (see reviews in McFadden et al., 2006a; Rodrigues et al., 2011; and in Rodrigues et al. in this same issue). As a consequence, $C$. neoformans has classically been classified in five different serotypes (A, B, C, D, and $\mathrm{AD}$ hybrid), based on the different antigenic properties of the capsular polysaccharide. The use of structural and analytical techniques, such as NMR or mass spectrometry has demonstrated that the capsular variation occurs at inter- and intra-strain levels (Cherniak et al., 1988a,b; McFadden et al., 2006b). The use of monoclonal antibodies that bind to the capsule has been extremely useful to understand the variability and complexity of this structure (Dromer et al., 1987; Eckert and Kozel, 1987; Todaro-Luck et al., 1989; van de Moer et al., 1990; Casadevall et al., 1992, 1994; Pirofski et al., 1995). Most of these mAbs have different affinities and specificities for different epitopes in the capsule, which indicates that the capsule 
has a complex and heterogeneous structure. Moreover, the epitope distribution for some of these Abs is not homogeneous through the capsule (Maxson et al., 2007b).

The use of mAbs has been of particular interest to show, not only the variability of the capsule between strains, but also how this structure changes in the same strain depending on the environment. McFadden et al. (2007) demonstrated that the binding of two different antibodies to the capsule changed when the fungal strain was grown in different media. Consistent with these findings, the capsule exhibits a high heterogeneity in the expression of epitopes, which depends on cell age, growth conditions, and serotype (Garcia-Hermoso et al., 2004; Gates-Hollingsworth and Kozel, 2009). The relationship between cell age and capsule structure is supported by the fact that the capsule of the buds is structurally different from the capsule of the mother cells (Pierini and Doering, 2001; Zaragoza et al., 2006; Gates-Hollingsworth and Kozel, 2009). Taken together, these findings clearly illustrate how the capsule is a dynamic structure that undergoes important rearrangements.

Changes of the capsule structure also occur in vivo, which suggest that these variations have consequences on the interaction with the host. A seminal article by Charlier et al. (2005) elegantly demonstrates how the capsule undergoes significant rearrangements during infection. The authors use two mAbs which present different in vitro serotype specificity (E1 mAb, which binds to serotype A, and CRND-8, which binds to serotype D). When animals are challenged with a serotype A strain, the fungus bound E1 mAb at early times of infection. After several days of infection, the binding specificity changed, and the fungal cells preferentially bound the CRND- $8 \mathrm{mAb}$. This evolution of the capsule structure seems to be organ specific (Garcia-Hermoso et al., 2004). Moreover, there is evidence that similar capsular rearrangements occur during human cryptococcal meningitis (Cherniak et al., 1995), where structural changes in the capsule of isolates from patients with recurrent cryptococcosis have been described. The molecular basis underlying the variability in capsule structures are not yet known.

The capsule can also significantly change the polysaccharide density. Many reports indicate that the density of the capsule varies according to its spatial distribution, being denser at the inner locations close to the cell wall (Pierini and Doering, 2001; Gates et al., 2004; Zaragoza et al., 2006; Maxson et al., 2007b). In addition, the density can significantly increase with cellular age and independently of capsule size (Maxson et al., 2007b). This change is associated with a higher resistance of the capsule to factors that induce its separation from the cell, such as $\gamma$-radiation, which suggests that increase in density is associated with a higher crosslinking of the polysaccharide fibers (Maxson et al., 2007b). Increase in polysaccharide density also occurs during infection (Gates et al., 2004).

\section{IMPORTANCE OF CAPSULE STRUCTURE CHANGES DURING THE INTERACTION WITH THE HOST}

The fact that capsule structure can change depending on the environmental conditions has profound consequences for the interaction with the host, since this structure is the first barrier recognized by the immune cells. An example of this situation is provided by the opsonic effect of some antibodies that do not bind to Fc receptors in the macrophages, such as IgM or Fab fragments, and that in consequence, are not opsonic by themselves. In these cases, the binding of the antibody produces a structural change in the capsule that exposes polysaccharide epitopes that can bind to CD18 and induce phagocytosis through the complement receptors (Netski and Kozel, 2002; Taborda and Casadevall, 2002). Conversely, changes in capsule structure alter the recognition of Abs. For example, changes in the acetylation can dramatically influence the binding of Abs to the capsule (Todaro-Luck et al., 1989; Kozel et al., 2003). Capsular differences between serotypes also influence the binding pattern of the same $\mathrm{Ab}$ (which can be annular or punctuate, depending on the serotype), and this correlates with opsonic efficiency and protection during infection (Cleare and Casadevall, 1998; Mukherjee et al., 1998). These findings suggest that if a specific adaptive response elicits certain Abs during infection, the ability to change the capsular structure will yield fungal cells which will not be recognized by those antibodies.

Changes in capsular structures occur during the cross of the brain-blood barrier, suggesting that capsular variations are required for dissemination and organ colonization (GarciaHermoso et al., 2004; Charlier et al., 2005).

In addition to $\mathrm{Ab}$ recognition, capsule structure affects the deposition of other molecules of the immune system. For example, the capsule is a potent inducer of the alternative pathway of complement activation, and it has been shown that differences in capsular structure influence the rate of complement deposition on the capsule. While all the serotypes accumulated the same amount of C3 molecules, the kinetics of the process was much faster when strains from serotypes $\mathrm{A}$ and $\mathrm{D}$ were used compared to strains from serotypes B and C (Young and Kozel, 1993).

The change in capsule density is another factor that determines some aspects of the interaction with the host. In particular, capsule density influences the penetration of different molecules of the immune system, such as complement or Abs, in the capsule, and affects the biological activity of these molecules (Zaragoza et al., 2003b; Gates and Kozel, 2006; Zaragoza and Casadevall, 2006). More recently, it has been demonstrated that a high degree of branching and viscosity of the capsule enhances some properties of the polysaccharide that are important during the interaction with the host, such as complement activation and phagocytosis avoidance, and the ability to act as a protective agent against free radicals (Cordero et al., 2011).

Another phenomenon that highlights the importance of capsule structure during infection is phenotypic switching. In $C$. neoformans, two different types of colony morphologies, smooth and mucoid, have been described (Goldman et al., 1998) that present differences in capsule viscosity (McFadden et al., 2007). These phenotypic variations are involved in virulence, since mucoid isolates are hypervirulent (Goldman et al., 1998; Guerrero et al., 2010).

Changes in capsular structure can influence not only the interaction between the yeast cells and the immune system, but can also affect the diagnosis of the infection. The most widely diagnostic tool used for cryptococcosis is based on serological tests which use reactive sera against the capsular polysaccharide which circulates in the serum. However, this circulating polysaccharide can change its structure over time, resulting in lack of reactivity, and false negative diagnoses (McFadden et al., 2004). 


\section{CHANGES IN CAPSULE SIZE}

A striking feature of the capsule is that it can undergo significant changes in its size according to the environmental conditions. This finding was first described in the 1950s (Littman, 1958), and in this work, a medium which produced capsule growth was described. More factors that induce capsule enlargement have been described, such as $\mathrm{CO}_{2}$, iron limitation, mammalian serum, low nutrient concentration at moderate basic $\mathrm{pH}$ and mannitol (Anna, 1979; Granger et al., 1985; Vartivarian et al., 1993; Zaragoza et al., 2003a; Zaragoza and Casadevall, 2004; Guimaraes et al., 2010). More importantly, while the capsule of C. neoformans is small in the environment and in regular laboratory conditions, it significantly increases in size after a few hours post-infection (Feldmesser et al., 2001).

Capsule enlargement represents a significant change for the cell. In cells with large capsule, this structure accounts for approximately 95\% of the total volume of the cell (Maxson et al., 2007a). Capsule enlargement is achieved by addition of new polysaccharide to the old capsule (Maxson et al., 2007b; Frases et al., 2009). An estimation of the mass of the capsule has been made, and it has been found that in media where the capsule enlarges, the total mass of the polysaccharide increases by a $20 \%$ in only a few hours. (Maxson et al., 2007a). These changes indicate that capsule enlargement is a dramatic change for the cell, and suggest that it is a high energy cost process. Structural studies have shown that the new polysaccharide fibers are different from the ones that are previously attached to the cell (Frases et al., 2008). Capsule growth is a regulated process, and does not occur indefinitely. After enlargement, the capsule size reaches a limit, which is directly proportional to the size of the cell body, delimited by the cell wall (Zaragoza et al., 2006).

\section{IMPORTANCE OF CAPSULE GROWTH DURING THE INTERACTION WITH THE HOST}

Capsule growth occurs during the first hours after being inhaled (Feldmesser et al., 2001), and is considered an "early" response of $C$. neoformans during the interaction with the host. Different studies have shown that this process confers advantages to the pathogen. By increasing the size of the capsule, the pathogen increases its total size, which may impair phagocytosis. However, phagocytosis of $C$. neoformans can occur in the presence of opsonins, such as proteins of the complement $(\mathrm{C})$ system or antibodies. In the case of $\mathrm{C}$-mediated phagocytosis, capsule enlargement plays a prominent role in determining the degree of internalization of the fungus. The localization of C3 protein, which is the main opsonin of the complement system involved in C. neoformans uptake, depends on the size of the capsule. In cells with small capsule, C3 binds at the edge of the capsule, a location which is accessible for the complement receptors (Zaragoza et al., 2003b), and phagocytosis occurs. However, when the capsule enlarges, C3 proteins bind deep in the capsule, several microns away from the edge, and is not accessible to the receptors (Zaragoza et al., 2003b). In this way, capsule enlargement promotes phagocytosis avoidance even in the presence of complement proteins.

Another role of capsule enlargement has been described during intracellular pathogenesis of $C$. neoformans. This fungal pathogen can evade killing by phagocytes once it has been internalized, and is considered a facultative intracellular pathogen (Diamond and Bennett, 1973; Levitz et al., 1999; Tucker and Casadevall, 2002). The mechanism of intracellular survival is still unknown. $C$. neoformans does not inhibit phagosome maturation or lysosome fusion and acidification (Levitz et al., 1999), which suggests that C. neoformans expresses some phenotypic traits that allow killing escape and survival. In this sense, capsule enlargement confers resistance to stress factors from the phago-lysosome, such as free radicals and antimicrobial peptides (Zaragoza et al., 2008). It is believed that capsule enlargement protects against free radicals by acting as a buffering structure. In cells with large capsule, free radicals would mainly exert their action on the capsular polysaccharide since it constitutes more than $90 \%$ of the volume of the cell (Maxson et al., 2007a). Since the capsule is not required for the normal growth of the yeast, alterations in the polysaccharide fibers by free radicals attack would result in increased survival compared to cells with small capsule. This idea is supported by the finding that capsule enlargement is in fact induced by macrophage factors (Ma et al., 2006; Chrisman et al., 2011).

\section{CHANGES IN THE TOTAL SIZE OF THE CELL}

Changes in the total cell size of C. neoformans occur during infection. Although C. neoformans is mainly found as rounded yeast cells in the host, the size of the blastoconidia found in the tissues (in particular, lungs) undergoes enormous variations. The regular cell size of $C$. neoformans cells in vitro ranges from 5 to $7 \mu \mathrm{m}$. During infection, sizes from 1 to $100 \mu \mathrm{m}$ are found (see Figure 1 and Cruickshank et al., 1973; Feldmesser et al., 2001). Hence, $C$. neoformans can produce both microforms and macro cells in the host. These variations have occasionally been described in the literature, but it has not been until recently that these types of cells have raised the interest of the scientific community. These phenomena are extremely interesting and suggest multiple consequences during the interaction with the host.

The best characterized phenomenon is the ability to form cells of a tremendous size in the lungs of infected mice. This transition is observed after several days of infection, so it could be considered as a "late" morphological response of the pathogen. Recently, two independent articles have characterized these cells in detail (Okagaki et al., 2010; Zaragoza et al., 2010). These articles defined them as "giant" or "titan" cells. So I will refer to them as fungal or cryptococcal "giant/titan cells." Using different approaches, these two groups show that fungal giant/titan cells are reproducibly found during infection, but their proportion is highly variable. During infection in murine models, where disseminated disease is accompanied by a strong inflammatory response, the proportion of fungal giant/titan cells is very low, around $5-10 \%$ of the total fungal burden. Okagaki et al. (2010) find that this proportion significantly increases when co-infections with MATa and MAT $\alpha$ mating types are performed, indicating that the pheromone signaling pathway plays an important role in the development of giant/titan cells. On the other hand, the proportion of cryptococcal giant/titan cells also increases when the fungal burden in the lungs is low and the mice develop chronic asymptomatic infection (Zaragoza et al., 2010). In addition, cAMP signaling pathway is required for cryptococcal giant/titan cell formation (Zaragoza et al., 2010). In agreement, other elements involved in the cAMP signaling pathway have been 
recently described to affect giant/titan cell formation, such as Ste3a and Gpr5 (G-protein coupled receptors), and the transcription factor Rim101 (Okagaki et al., 2011). Moreover, analysis of a collection of gene deletion mutants have identified other proteins involved in cellular enlargement, like G1 cyclins, Rho-GTPases, and GTPases-activating proteins, suggesting that titan formation requires the interplay of different pathways in the cell (Okagaki et al., 2011). Ras1 and MAPK signaling pathway do not seem to participate in giant/titan cell induction (Zaragoza et al., 2010; Okagaki et al., 2011). Fungal giant/titan cells are polyploid (Okagaki et al., 2010; Zaragoza et al., 2010), suggesting that the formation of these cells is achieved by endoreduplication, a well known process that yields cells of enormous size. In addition to an increase in the DNA content, fungal giant/titan cells present other phenotypic differences compared to regular cells. The capsule of titan cells has a higher polysaccharide density and presents different antigenic properties compared to cells grown in vitro (Zaragoza et al., 2010). In addition, the cell wall is significantly thicker, reaching a width of 2-3 $\mathrm{mm}$ (Zaragoza et al., 2010). Titan cells present peculiar intracellular features, such as the presence of a fragmented vacuole. Cryptococcal giant/titan cell formation is achieved not only by an increase in the capsule size, but also in the cell body size, which in some cases could reach a diameter of $100 \mu \mathrm{m}$ (Okagaki et al., 2010).

Besides the formation of titan cells, C. neoformans can also form micro-cells, of a size lower than $1 \mu \mathrm{m}$ (Feldmesser et al., 2001). These cells have not been studied in detail, but they are a common feature of the C. neoformans infection. The fact that C. neoformans can exhibit giant/titan and micro-cells during infection suggests that this pathogen has developed a complex morphogenetic program that allows adaptation to the host environment.

\section{IMPORTANCE OF CHANGES IN TOTAL CELL SIZE DURING THE INTERACTION WITH THE HOST}

The presence of cryptococcal giant/titan cells during infection represents a multilevel problem for the immune system. These cells present a higher resistance to oxidative agents (Okagaki et al., 2010; Zaragoza et al., 2010). In addition, titan cells avoid phagocytosis, although macrophages seem to recognize and bind to these fungal cellular forms (see Figure 2 and Okagaki et al., 2010; Zaragoza et al., 2010). These two features confirm that cryptococcal giant/titan cells can evade the host immune system. However, the role of these cells in the pathogenesis of the yeast is still unclear. Co-infection with MATa and MAT $\alpha$ cells produced an increase in the proportion of fungal giant/titan cells in the lung, and this correlated with decreased dissemination of the fungus to the brain (Okagaki et al., 2010), suggesting that their large size impairs their ability to exit the lungs and cross biological barriers. During chronic infection, where a low number of yeasts are found in the lungs and there is no inflammation, the proportion of fungal giant cells was around 70-90\% (Zaragoza et al., 2010). These observations suggest that, in fact, fungal giant/titan cells are not involved in the development of a disseminated disease. Instead, they provide fungal resistant forms that can persist in the host for long time periods. However, recent findings demonstrate that fungal giant/titan cells are virulent in the non conventional host Galleria mellonella (Garcia-Rodas et al., 2011), suggesting that this

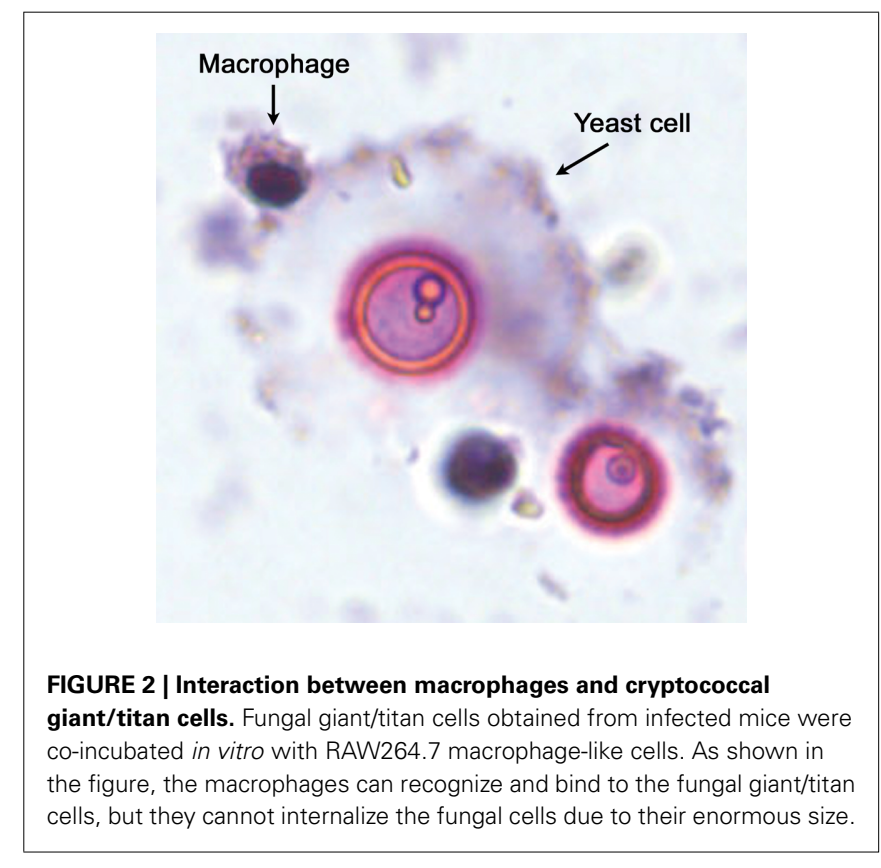

type of cells can also contribute to the development of the disease in certain situations, most probably by producing a progeny of cells of regular size.

Cryptococcal giant/titan cells have been also described in other model hosts. Recently, it has been found that incubation of $C$. neoformans in ameba extracts results in capsule enlargement (Chrisman et al., 2011), and occasionally, also in the appearance of titan cells (Chrisman et al., 2011). Furthermore, unpublished results from our group indicate that during infection in the nonconventional host Galleria mellonella, C. neoformans also forms giant/titan cells (Garcia-Rodas et al., 2011). These findings indicate that gigantism is a general feature elicited by $C$. neoformans that occurs during infection in different types of hosts, which highlights the idea that this morphological transition plays an important role in fungal survival and persistence in the host.

Cryptococcus neoformans can also produce cells of a smaller size, known as micro-cells. Although their role in virulence has not been described, their presence during infection raises challenging questions. For example, it is tempting to hypothesize that due to their reduced size, these cells could have a particular ability to disseminate and cross biological barriers, such as endothelia and the brain-blood barrier, and in consequence, contribute to the development of cryptococcal meningitis.

\section{FINAL REMARKS ABOUT THE ROLE OF MORPHOLOGICAL AND PHENOTYPIC VARIATIONS IN DIFFERENT PHASES OF THE INFECTION AND DISEASE CAUSED BY CRYPTOCOCCUS NEOFORMANS}

As it has been described in this review, C. neoformans can produce a large number of phenotypic forms by inducing changes in the structure and/or size of the capsule, and in the total size of the cell. These changes have profound effects during the interaction with the host. They contribute to immune evasion, adaptation to the host environment, dissemination, and long term survival 
during infection. These phenotypic and morphological variations constitute mechanisms that contribute to the cryptococcal infection, in addition to the well established role of the cryptococcal exopolysaccharide as a virulence factor (see review in Zaragoza et al., 2009). The molecular mechanisms involved in the regulation of these changes, and their contribution to the cryptococcal pathogenesis remain unknown, but it is reasonable to hypothesize that they participate in different states of the cryptococcal disease. After the first contact of the yeast with the host, capsule enlargement (an "early" response of the fungus) contributes to phagocytosis escape and intracellular survival, which allows the yeast to evade the first line of defense elicited by the host. In immunocompetent hosts, the infection is controlled, but the fungal cells are not completely cleared, and it is believed that $C$. neoformans can develop a latent state (Dromer et al., 2011). In these conditions, the production of fungal giant/titan cells (a "late" fungal response) could be a key factor to ensure long term survival. During the most typical clinical manifestation, which is dissemination and meningitis, morphological changes also contribute to the disease. First, the ability to produce capsular rearrangements contributes to the avoidance of recognition by immune cells and antibodies. In addition, capsular rearrangements seem to contribute to yeast dissemination and cross of biological barriers. The capacity to produce micro-cells could also facilitate the dissemination of the fungus and the consequent invasion of the brain. Finally, the large number of different yeast forms that could be found during infection could also play a role in another well known disease caused by C. neoformans, which is the immune reconstitution inflammatory syndrome (IRIS) also known as immune restoration disease (IRD). This is a disease developed by some HIV patients who recover their immune system after the initiation of the HAART. In these conditions, if an infection is encountered by the immune system, an exaggerated inflammatory response is elicited, which develops an acute disease. The pathogens which are associated with this disorder are Mycobacterium tuberculosis and C. neoformans (French, 2009), most probably because their incidence is particularly significant among HIV patients. In the case of $C$. neoformans, I hypothesize that in situations of immune recovery, the presence of multiple variants of cryptococcal cells, with different capsule structures and cell sizes may elicit multiple

\section{REFERENCES}

Aksenov, S. I., Babyeva, I. P., and Golubev, V. I. (1973). On the mechanism of adaptation of microorganisms to conditions of extreme low humidity. Life Sci. Space Res. 11, 55-61.

Anna, E. J. (1979). Rapid in vitro capsule production by cryptococci. Am. J. Med. Technol. 45, 585-588.

Bose, I., Reese, A. J., Ory, J. J., Janbon, G., and Doering, T. L. (2003). A yeast under cover: the capsule of Cryptococcus neoformans. Eukaryot. Cell 2, 655-663.

Casadevall, A., Deshaw, M., Fan, M., Dromer, F., Kozel, T. R., and Pirofski, L. A. (1994). Molecular and idiotypic

immune responses simultaneously, which can contribute to the appearance of the IRIS.

\section{FUTURE PERSPECTIVES}

In conclusion, although $C$. neoformans has not been classically considered a fungus able to undergo morphological changes, it can in fact elicit multiple cellular types which contribute to the survival of the yeast in vivo. Although some effects of cryptococcal morphogenesis have been described, many important questions still need to be addressed. These transitions have been described in vitro and in murine models, but their presence during human infection has not been fully demonstrated. Clinical and histopathological studies are needed to confirm the occurrence of capsular variations and the formation of micro- and giant/titan cells in humans. In addition, the cellular mechanisms that regulate the variations in structure and size of the capsule and the formation of fungal giant/titan and micro-cells are unknown, and future studies are required to unveil these molecular processes. For this purpose, it is necessary to better characterize the genes involved in capsule synthesis, and in particular, the interplay between them. The finding that vesicle secretion is involved in capsule synthesis suggests that exocytosis processes might be involved in capsular rearrangements, and that induction or inhibition of extracellular transport could result in variations of capsule structure. Concerning the changes in total cell size, the formation of cryptococcal giant/titan and micro-cells implies that $C$. neoformans can induce alterations in their cell cycle, to undergo endoreduplication (to produce gigantic cells), or to reduce the length of the cell cycle (to produce micro-cells). The idea that cell cycle regulation depends on host factors is a challenging hypothesis that deserves special interest in future studies. To conclude, the full characterization of morphological changes in C. neoformans, and in particular, the elucidation of the molecular mechanisms involved in these processes will also contribute to the design of new therapeutical strategies.

\section{ACKNOWLEDGMENTS}

I warmly thank my colleague and friend Helene Eisenman for her careful critical reading of the manuscript and for her helpful suggestions. Oscar Zaragoza is funded by grant SAF2008-03761 from the Spanish Ministry of Science and Innovation.

its virulence. Mol. Cell. Biol. 14, 4912-4919.

Chang, Y. C., and Kwon-Chung, K. J. (1998). Isolation of the third capsule-associated gene, CAP60, required for virulence in Cryptococcus neoformans. Infect. Immun. 66, 2230-2236.

Chang, Y. C., and Kwon-Chung, K. J. (1999). Isolation, characterization, and localization of a capsuleassociated gene, CAP10, of Cryptococcus neoformans. J. Bacteriol. 181, 5636-5643.

Chang, Y. C., Wickes, B. L., and KwonChung, K. J. (1995). Further analysis of the CAP59 locus of Cryptococcus neoformans: structure defined by forced expression and description of a new ribosomal protein-encoding gene. Gene 167, 179-183.

Charlier, C., Chretien, F., Baudrimont, M., Mordelet, E., Lortholary, O., and Dromer, F. (2005). Capsule structure changes associated with Cryptococcus neoformans crossing of the blood-brain barrier. Am. J. Pathol. 166, 421-432.

Cherniak, R., Jones, R. G., and Reiss, E. (1988a). Structure determination of Cryptococcus neoformans serotype A-variant glucuronoxylomannan by 13C-n.m.r. spectroscopy. Carbohydr. Res. 172, 113-138.

Cherniak, R., Jones, R. G., and Slodki, M. E. (1988b). Typespecific polysaccharides of Cryptococcus neoformans. n.m.r.-spectral 
study of a glucuronomannan chemically derived from a Tremella mesenterica exopolysaccharide. Carbohydr. Res. 182, 227-239.

Cherniak, R., Morris, L. C., Belay, T., Spitzer, E. D., and Casadevall, A. (1995). Variation in the structure of glucuronoxylomannan in isolates from patients with recurrent cryptococcal meningitis. Infect. Immun. 63, 1899-1905.

Cherniak, R., Reiss, E., Slodki, M. E., Plattner, R. D., and Blumer, S. O. (1980). Structure and antigenic activity of the capsular polysaccharide of Cryptococcus neoformans serotype A. Mol. Immunol. 17, 1025-1032.

Cherniak, R., Reiss, E., and Turner, S. (1982). A galactoxylomannan antigen of Cryptococcus neoformans serotype A. Carbohydr. Res. 103, 239-250.

Cherniak, R., and Sundstrom, J. B. (1994). Polysaccharide antigens of the capsule of Cryptococcus neoformans. Infect. Immun. 62, 1507-1512.

Cherniak, R., Valafar, H., Morris, L. C., and Valafar, F. (1998). Cryptococcus neoformans chemotyping by quantitative analysis of $1 \mathrm{H}$ nuclear magnetic resonance spectra of glucuronoxylomannans with a computer-simulated artificial neural network. Clin. Diagn. Lab. Immunol. 5, 146-159.

Chrisman, C. J., Albuquerque, P., Guimaraes, A. J., Nieves, E., and Casadevall, A. (2011). Phospholipids trigger Cryptococcus neoformans capsular enlargement during interactions with amoebae and macrophages. PLoS Pathog. 7, e1002047. doi: 10.1371/journal.ppat.1002047

Cleare, W., and Casadevall, A. (1998). The different binding patterns of two immunoglobulin $\mathrm{M}$ monoclonal antibodies to Cryptococcus neoformans serotype A and D strains correlate with serotype classification and differences in functional assays. Clin. Diagn. Lab. Immunol. 5, 125-129.

Cordero, R. J., Frases, S., Guimaraes, A. J., Rivera, J., and Casadevall, A. (2011). Evidence for branching in cryptococcal capsular polysaccharides and consequences on its biological activity. Mol. Microbiol. 79, 1101-1117.

Cruickshank, J. G., Cavill, R., and Jelbert, M. (1973). Cryptococcus neoformans of unusual morphology. Appl. Microbiol. 25, 309-312.

De Jesus, M. D., Nicola, A. M., Chow, S. K., Lee, I. R., Nong, S., Specht, C. A., Levitz, S. M., and Casadevall,
A. (2010). Glucuronoxylomannan, galactoxylomannan, and mannoprotein occupy spatially separate and discrete regions in the capsule of Cryptococcus neoformans. Virulence 1, 500-508.

Diamond, R. D., and Bennett, J. E. (1973). Growth of Cryptococcus neoformans within human macrophages in vitro. Infect. Immun. 7, 231-236.

Doering, T. L. (2000). How does Cryptococcus get its coat? Trends Microbiol. 8, 547-553.

Dromer, F., Casadevall, A., Perfect, J. R., and Sorrell, T. C. (2011). "Cryptococcus neoformans: latency and disease," in Cryptococcus. From Human Pathogen to Model Yeast, eds J. Heitman, T. R. Kozel, K. J. KwonChung, J. R. Perfect, and A. Casadevall (Washington, DC: ASM Press), 431-439.

Dromer, F., Charreire, J., Contrepois, A., Carbon, C., and Yeni, P. (1987). Protection of mice against experimental cryptococcosis by anti-Cryptococcus neoformans monoclonal antibody. Infect. Immun. 55, 749-752.

Dromer, F., Mathoulin-Pelissier, S., Launay, O., and Lortholary, O. (2007) Determinants of disease presentation and outcome during cryptococcosis: the CryptoA/D study. PLoS Med. 4, e21. doi: 10.1371/journal.pmed.0040021

Eckert, T. F., and Kozel, T. R. (1987). Production and characterization of monoclonal antibodies specific for Cryptococcus neoformans capsular polysaccharide. Infect. Immun. 55, 1895-1899.

Ellerbroek, P. M., Hoepelman, A. I., Wolbers, F., Zwaginga, J. J., and Coenjaerts, F. E. (2002). Cryptococcal glucuronoxylomannan inhibits adhesion of neutrophils to stimulated endothelium in vitro by affecting both neutrophils and endothelial cells. Infect. Immun. 70, 4762-4771.

Feldmesser, M., Kress, Y., and Casadevall, A. (2001). Dynamic changes in the morphology of Cryptococcus neoformans during murine pulmonary infection. Microbiology 147 , 2355-2365.

Frases, S., Nimrichter, L., Viana, N. B., Nakouzi, A., and Casadevall, A. (2008). Cryptococcus neoformans capsular polysaccharide and exopolysaccharide fractions manifest physical, chemical, and antigenic differences. Eukaryot. Cell 7, 319-327.

Frases, S., Pontes, B., Nimrichter, L., Viana, N. B., Rodrigues, M. L., and Casadevall, A. (2009). Capsule of Cryptococcus neoformans grows by enlargement of polysaccharide molecules. Proc. Natl. Acad. Sci. U.S.A. 106, 1228-1233.

French, M. A. (2009). HIV/AIDS: immune reconstitution inflammatory syndrome: a reappraisal. Clin. Infect. Dis. 48, 101-107.

Gahrs, W., Tigyi, Z., Emody, L., and Makovitzky, J. (2009). Polarization optical analysis of the surface structures of various fungi. Acta Histochem. 111, 308-315.

Garcia-Hermoso, D., Dromer, F., and Janbon, G. (2004). Cryptococcus neoformans capsule structure evolution in vitro and during murine infection. Infect. Immun. 72, 3359-3365.

Garcia-Rodas, R., Casadevall, A., Rodriguez-Tudela, J. L., CuencaEstrella, M., and Zaragoza, O. (2011). Cryptococcus neoformans capsular enlargement and cellular gigantism during Galleria mellonella infection. PLoS ONE (in press).

Gates, M. A., and Kozel, T. R (2006). Differential localization of complement component 3 within the capsular matrix of Cryptococcus neoformans. Infect. Immun. 74, 3096-3106.

Gates, M. A., Thorkildson, P., and Kozel, T. R. (2004). Molecular architecture of the Cryptococcus neoformans capsule. Mol. Microbiol. 52, 13-24.

Gates-Hollingsworth, M. A., and Kozel, T. R. (2009). Phenotypic heterogeneity in expression of epitopes in the Cryptococcus neoformans capsule. Mol. Microbiol. 74 126-138.

Gazzoni, A. F., Oliveira Fde, M., Salles, E. F., Mayayo, E., Guarro, J., Capilla, J., and Severo, L. C. (2010). Unusual morphologies of Cryptococcus spp. in tissue specimens: report of 10 cases. Rev. Inst. Med. Trop. Sao Paulo 52, 145-149.

Goldman, D. L., Fries, B. C., Franzot, S. P., Montella, L., and Casadevall, A. (1998). Phenotypic switching in the human pathogenic fungus Cryptococcus neoformans is associated with changes in virulence and pulmonary inflammatory response in rodents. Proc. Natl. Acad. Sci. U.S.A. 95, 14967-14972.

Granger, D. L., Perfect, J. R., and Durack, D. T. (1985). Virulence of Cryptococcus neoformans. Regulation of capsule synthesis by carbon dioxide. J. Clin. Invest. 76 , 508-516.

Guerrero, A., Jain, N., Wang, X. and Fries, B. C. (2010). Cryptococcus neoformans variants generated by phenotypic switching differ in virulence through effects on macrophage activation. Infect. Immun. 78, 1049-1057.
Guimaraes, A. J., Frases, S., Cordero, R. J., Nimrichter, L., Casadevall, A., and Nosanchuk, J. D. (2010). Cryptococcus neoformans responds to mannitol by increasing capsule size in vitro and in vivo. Cell. Microbiol. 12 740-753.

Heiss, C., Klutts, J. S., Wang, Z., Doering, T. L., and Azadi, P. (2009). The structure of Cryptococcus neoformans galactoxylomannan contains betaD-glucuronic acid. Carbohydr. Res. 344, 915-920.

Heitman, J., Kozel, T. R., Kwon-Chung, K. J., Perfect, J. R., and Casadevall, A. (2011). Cryptococcus. From Human Pathogen to Model Yeast. Washington, DC: ASM Press.

Hosseini-Moghaddam, S. M., and Husain, S. (2010). Fungi and molds following lung transplantation. Semin. Respir. Crit. Care Med. 31, 222-233.

Janbon, G. (2004). Cryptococcus neoformans capsule biosynthesis and regulation. FEMS Yeast Res. 4 , 765-771.

Janbon, G., and Doering, T. L. (2011). "Biosynthesis and genetics of the Cryptococcus capsule," in Cryptococcus. From human Pathogen to Model Yeast, eds J. Heitman, T. R. Kozel, K. J. Kwon-Chung, J. R. Perfect, and A. Casadevall (Washington, DC: ASM Press), 27-41.

Janbon, G., Himmelreich, U., Moyrand, F., Improvisi, L., and Dromer, F. (2001). Caslp is a membrane protein necessary for the $\mathrm{O}$-acetylation of the Cryptococcus neoformans capsular polysaccharide. Mol. Microbiol. 42, 453-467.

Kane, J. (1984). Conversion of Blastomyces dermatitidis to the yeast form at 37 degrees $\mathrm{C}$ and 26 degrees C. J. Clin. Microbiol. 20, 594-596.

Kozel, T. R., Gulley, W. F., and Cazin, J. Jr. (1977). Immune response to Cryptococcus neoformans soluble polysaccharide: immunological unresponsiveness. Infect. Immun. 18, 701-707.

Kozel, T. R., Levitz, S. M., Dromer, F. Gates, M. A., Thorkildson, P., and Janbon, G. (2003). Antigenic and biological characteristics of mutant strains of Cryptococcus neoformans lacking capsular $\mathrm{O}$ acetylation or xylosyl side chains. Infect. Immun. 71, 2868-2875.

Kozubowski, L., and Heitman, J. (2011). Profiling a killer, the development of Cryptococcus neoformans. FEMS Microbiol. Rev. doi: 10.1111/j.15746976.2011.00286.x. [Epub ahead of print].

Kurtzman, C. P., and Fell, J. W. (1997). The Yeasts: A Taxonomical Study. Amsterdam: Elsevier. 
Levitz, S. M., Nong, S. H., Seetoo, K. F., Harrison, T. S., Speizer, R. A. and Simons, E. R. (1999). Cryptococcus neoformans resides in an acidic phagolysosome of human macrophages. Infect. Immun. 67, 885-890.

Levitz, S. M., and Specht, C. A. (2006). The molecular basis for the immunogenicity of Cryptococcus neoformans mannoproteins. FEMS Yeast Res. 6, 513-524.

Lipovsky, M. M., Tsenova, L., Coenjaerts, F. E., Kaplan, G., Cherniak, R., and Hoepelman, A. I. (2000). Cryptococcal glucuronoxylomannan delays translocation of leukocytes across the blood-brain barrier in an animal model of acute bacterial meningitis. J. Neuroimmunol. 111, 10-14.

Littman, M. (1958). Capsule synthesis by Cryptococcus neoformans. Trans. N. Y. Acad. Sci. 20, 623-648.

Liu, O. W., Chun, C. D., Chow, E. D., Chen, C., Madhani, H. D., and Noble, S. M. (2008). Systematic genetic analysis of virulence in the human fungal pathogen Cryptococcus neoformans. Cell 135, 174-188.

Ma, H., Croudace, J. E., Lammas, D. A., and May, R. C. (2006). Expulsion of live pathogenic yeast by macrophages. Curr. Biol. 16, 2156-2160.

Macher, A. M., Bennett, J. E., Gadek, J. E., and Frank, M. M. (1978). Complement depletion in cryptococcal sepsis. J. Immunol. 120, 1686-1690.

Maresca, B., and Kobayashi, G. S. (1989). Dimorphism in Histoplasma capsulatum: a model for the study of cell differentiation in pathogenic fungi. Microbiol. Rev. 53, 186-209.

Maxson, M. E., Cook, E., Casadevall, A., and Zaragoza, O. (2007a). The volume and hydration of the Cryptococcus neoformans polysaccharide capsule. Fungal Genet. Biol. 44, 180-186.

Maxson, M. E., Dadachova, E., Casadevall, A., and Zaragoza, O. (2007b). Radial mass density, charge, and epitope distribution in the Cryptococcus neoformans capsule. Eukaryot. Cell 6, 95-109.

McFadden, D., Zaragoza, O., and Casadevall, A. (2006a). The capsular dynamics of Cryptococcus neoformans. Trends Microbiol. 14, 497-505.

McFadden, D. C., De Jesus, M., and Casadevall, A. (2006b). The physical properties of the capsular polysaccharides from Cryptococcus neoformans suggest features for capsule construction. J. Biol. Chem. 281, 1868-1875.
McFadden, D. C., Fries, B. C., Wang, F., and Casadevall, A. (2007). Capsule structural heterogeneity and antigenic variation in Cryptococcus neoformans. Eukaryot. Cell 6, 1464-1473.

McFadden, D. C., Zaragoza, O., and Casadevall, A. (2004). Immunoreactivity of cryptococcal antigen is not stable under prolonged incubations in human serum. J. Clin. Microbiol. 42, 2786-2788.

Monari, C., Bistoni, F., and Vecchiarelli, A. (2006). Glucuronoxylomannan exhibits potent immunosuppressive properties. FEMS Yeast Res. 6, 537-542.

Mukherjee, J., Kozel, T. R., and Casadevall, A. (1998). Monoclonal antibodies reveal additional epitopes of serotype D Cryptococcus neoformans capsular glucuronoxylomannan that elicit protective antibodies. J. Immunol. 161, 3557-3568.

Murphy, J. W., and Cozad, G. C. (1972). Immunological unresponsiveness induced by cryptococcal capsular polysaccharide assayed by the hemolytic plaque technique. Infect. Immun. 5, 896-901.

Neilson, J. B., Ivey, M. H., and Bulmer, G. S. (1978). Cryptococcus neoformans: pseudohyphal forms surviving culture with Acanthamoeba polyphaga. Infect. Immun. 20, 262-266.

Netski, D., and Kozel, T. R. (2002). Fc-dependent and Fc-independent opsonization of Cryptococcus neoformans by anticapsular monoclonal antibodies: importance of epitope specificity. Infect. Immun. 70, 2812-2819.

Nimrichter, L., Frases, S., Cinelli, L. P., Viana, N. B., Nakouzi, A., Travassos, L. R., Casadevall, A., and Rodrigues, M. L. (2007). Self-aggregation of Cryptococcus neoformans capsular glucuronoxylomannan is dependent on divalent cations. Eukaryot. Cell 6, 1400-1410.

Nosanchuk, J. D., and Casadevall, A. (2003). The contribution of melanin to microbial pathogenesis. Cell. Microbiol. 5, 203-223.

Okagaki, L. H., Strain, A. K., Nielsen, J. N., Charlier, C., Baltes, N. J., Chretien, F., Heitman, J., Dromer F., and Nielsen, K. (2010). Cryptococcal cell morphology affects host cell interactions and pathogenicity. PLoS Pathog. 6, e1000953. doi: 10.1371/journal.ppat.1000953

Okagaki, L. H., Wang, Y., Ballou, E. R., O'meara, T. R., Bahn, Y. S., Alspaugh, J. A., Xue, C., and Nielsen, K. (2011). Cryptococcal titan cell formation is regulated by G-protein signaling in response to multiple stimuli. Eukaryot. Cell. doi: 10.1128/EC.05179-11. [Epub ahead of print].

Park, B. I., Wannemuehler, K. A., Marston, B. J., Govender, N., Pappas, P. G., and Chiller, T. M. (2009). Estimation of the current global burden of cryptococcal meningitis among persons living with HIV/AIDS. AIDS 23, 525-530.

Pierini, L. M., and Doering, T. L. (2001). Spatial and temporal sequence of capsule construction in Cryptococcus neoformans. Mol. Microbiol. 41, 105-115.

Pirofski, L., Lui, R., Deshaw, M., Kressel, A. B., and Zhong, Z. (1995). Analysis of human monoclonal antibodies elicited by vaccination with a Cryptococcus neoformans glucuronoxylomannan capsular polysaccharide vaccine. Infect. Immun 63, 3005-3014.

Rodrigues, M. L., Alvarez, M., Fonseca, F. L., and Casadevall, A. (2008). Binding of the wheat germ lectin to Cryptococcus neoformans suggests an association of chitinlike structures with yeast budding and capsular glucuronoxylomannan. Eukaryot. Cell 7, 602-609.

Rodrigues, M. L., Casadevall, A., and Zaragoza, O. (2011). "The architecture and antigenic composition of the polysaccharide capsule," in Cryptococcus. From Human Pathogen to Model Yeast, eds J. Heitman, T. R. Kozel, K. J. Kwon-Chung, J. R. Perfect, and A. Casadevall (Washington, DC: ASM Press), 43-54.

Rodrigues, M. L., Nimrichter, L. Oliveira, D. L., Frases, S., Miranda, K., Zaragoza, O., Alvarez, M. Nakouzi, A., Feldmesser, M., and Casadevall, A. (2007). Vesicular polysaccharide export in Cryptococcus neoformans is a eukaryotic solution to the problem of fungal transcell wall transport. Eukaryot. Cell 6 , 48-59.

Singh, N., and Forrest, G. (2009). Cryptococcosis in solid organ transplant recipients. Am. J. Transplant. 9(Suppl. 4), S192-S198.

Taborda, C. P., and Casadevall, A. (2002). CR3 (CD11b/CD18) and CR4 (CD11c/CD18) are involved in complement-independent antibody-mediated phagocytosis of Cryptococcus neoformans. Immunity 16, 791-802.

Todaro-Luck, F., Reiss, E., Cherniak, R. and Kaufman, L. (1989). Characterization of Cryptococcus neoformans capsular glucuronoxylomannan polysaccharide with monoclonal antibodies. Infect. Immun. 57, 3882-3887.
Tucker, S. C., and Casadevall, A. (2002). Replication of Cryptococcus neoformans in macrophages is accompanied by phagosomal permeabilization and accumulation of vesicles containing polysaccharide in the cytoplasm. Proc. Natl. Acad. Sci. U.S.A. 99, 3165-3170.

van de Moer, A., Salhi, S. L., Cherniak, R., Pau, B., Garrigues, M L., and Bastide, J. M. (1990). An anti-Cryptococcus neoformans monoclonal antibody directed against galactoxylomannan. Res. Immunol. 141, 33-42.

Vartivarian, S. E., Anaissie, E. J., Cowart, R. E., Sprigg, H. A., Tingler, M. J., and Jacobson, E. S. (1993). Regulation of cryptococcal capsular polysaccharide by iron. J. Infect. Dis. 167, 186-190.

Vecchiarelli, A. (2000). Immunoregulation by capsular components of Cryptococcus neoformans. Med. Mycol. 38, 407-417.

Whiteway, M., and Bachewich, C. (2007). Morphogenesis in Candida albicans. Annu. Rev. Microbiol. 61, 529-553.

Williamson, J. D., Silverman, J. F., Mallak, C. T., and Christie, J. D. (1996). Atypical cytomorphologic appearance of Cryptococcus neoformans: a report of five cases. Acta Cytol. 40, 363-370.

Young, B. J., and Kozel, T. R. (1993). Effects of strain variation, serotype, and structural modification on kinetics for activation and binding of C3 to Cryptococcus neoformans. Infect. Immun. 61, 2966-2972.

Zaragoza, O., and Casadevall, A. (2004). Experimental modulation of capsule size in Cryptococcus neoformans. Biol. Proced. Online 6 , 10-15.

Zaragoza, O., and Casadevall, A. (2006) Monoclonal antibodies can affect complement deposition on the capsule of the pathogenic fungus Cryptococcus neoformans by both classical pathway activation and steric hindrance. Cell. Microbiol. 8 , 1862-1876

Zaragoza, O., Chrisman, C. J., Castelli, M. V., Frases, S., Cuenca-Estrella, M., Rodriguez-Tudela, J. L., and Casadevall, A. (2008). Capsule enlargement in Cryptococcus neoformans confers resistance to oxidative stress suggesting a mechanism for intracellular survival. Cell. Microbiol. 10, 2043-2057.

Zaragoza, O., Fries, B. C., and Casadevall, A. (2003a). Induction of capsule growth in Cryptococcus neoformans by mammalian serum and $\mathrm{CO}(2)$. Infect. Immun. 71, 6155-6164. 
Zaragoza, O., Taborda, C. P., and Casadevall, A. (2003b). The efficacy of complement-mediated phagocytosis of Cryptococcus neoformans is dependent on the location of C3 in the polysaccharide capsule and involves both direct and indirect $\mathrm{C} 3$-mediated interactions. Eur. J. Immnunol. 33, 1957-1967.

Zaragoza, O., Garcia-Rodas, R. Nosanchuk, J. D., Cuenca-Estrella, M., Rodriguez-Tudela, J. L., and Casadevall, A. (2010). Fungal cell gigantism during mammalian infection. PLoS Pathog. 6, e1000945. doi: 10.1371/journal. ppat.1000945

Zaragoza, O., Rodrigues, M. L., De Jesus, M., Frases, S., Dadachova, E., and Casadevall, A. (2009). The capsule of the fungal pathogen Cryptococcus neoformans. Adv. Appl. Microbiol. 68 133-216.

Zaragoza, O., Telzak, A., Bryan, R. A., Dadachova, E., and Casadevall, A. (2006). The polysaccharide capsule of the pathogenic fungus Cryptococcus neoformans enlarges by distal growth and is rearranged during budding. Mol. Microbiol. 59, 67-83.

Conflict of Interest Statement: The author declares that the research was conducted in the absence of any commercial or financial relationships that could be construed as a potential conflict of interest.

Received: 12 July 2011; accepted: 17 August 2011; published online: 06 September 2011.

Citation: Zaragoza O (2011) Multiple disguises for the same party: the concepts of morphogenesis and phenotypic variations in Cryptococcus neoformans. Front. Microbio. 2:181. doi: 10.3389/fmicb.2011.00181

This article was submitted to Frontiers in Fungi and Their Interactions, a specialty of Frontiers in Microbiology.

Copyright (c) 2011 Zaragoza. This is an open-access article subject to a nonexclusive license between the authors and Frontiers Media SA, which permits use, distribution and reproduction in other forums, provided the original authors and source are credited and other Frontiers conditions are complied with. 